Mauricio Léniz

Claudia Paublo

Ubicación Av La Dehesa 2035, Lo Barnechea, Santiago Mandante Patricia Ready

Cálculo Estructural Juan López

Constructora RyH

Materialidad Tabiquerías, hormisón visto, vidrio, acero,

piedra pizarra y parquet flotante blanco.

Superficie remodelación $240 \mathrm{~m}^{2}$

Año Proyecto 2001

Año construcción 2001

Fotografías Patricio Mardones

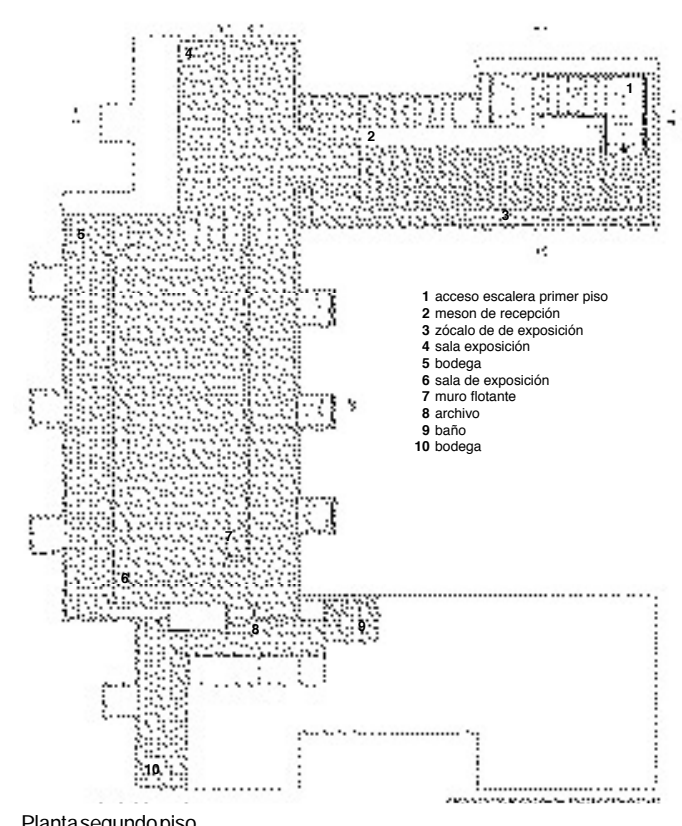

Plantasegundo piso

\title{
Remodelación Galería de Arte Patricia Ready
}

El proyecto consiste en una remodelaci-n interior para habilitar la mansarda de una casa de estilo y transformarla en una galer'a de arte.

Eldise-o deb'a resolverdos situaciones complejas dado el contexto de la casa existente:

1. Elacceso est‡ en el primer piso y el es pacio de la galer'a es $\$$ en el segundo. Hab’a que resolver esta transici-n de alguna manera.

2. El espacio del techo y su car $\neq$ cter de $\ddagger$ tico deb'a solucionarse de tal forma que la percepci-n de estar dentro de una mansarda se olvidara.

El proyecto se dividi-en tres instancias: el acceso, un espacio de llegada y la sala de exposiciones, cada una caracterizada de una manera distinta.

Se dise- - entonces una secuencia de situaciones interiores de luz y materialida des que desconectaran al visitante de la imagen de casa georgian en el exterior. Todos los elementos que componen el acceso es $t \neq n$ dise-ados pensando en que se reconocieran como muebles en tŽrminos de sus detalles yde suescala.

En el espacio de llegada se propone una recepci-n y un estar. Se construy-un mes-nde siete metros de largo en hormig-nvisto para tener computadores conectados a la web y revistas de arte. El cielo a dos aguas se transform-en $b-v e d a$ independiz $\neq$ ndose de la geometr'a de la mansarda.

La sala de exposiciones tambižn reconstruye la conpguraci-n de los cielos. $f$ stos bajaron a tres metros de altura elimin $¥$ ndose las pendientes interiores. Por otra parte se dispuso longitudinalmente al espacio de exposici-n un muro ßotante a la manera de un biombo para aumentar la superpcie de exhibici-n y depnir una circulaci-n. Se dise-aron tambižn espacios de archivo, servicios yuna opcina.

Mauricio Léniz

Aquitecto Pontipcia Universidad Cat-lica de Chile, 1996. Ha sido profeso de dibujo y taller en la P.U.C.; actualmente es profesor de Taller de DiseIndustrial en la Escuela de Dise- o de la Universidad Diego Portales.

Claudia Paublo

Arquitecto Pontipcia Universidad Cat-licade Chile, 1999. Actualmente es profesora de taller de Dise-o Industrial en la Escuela de Dise-o de la Universidad Diego Portales.
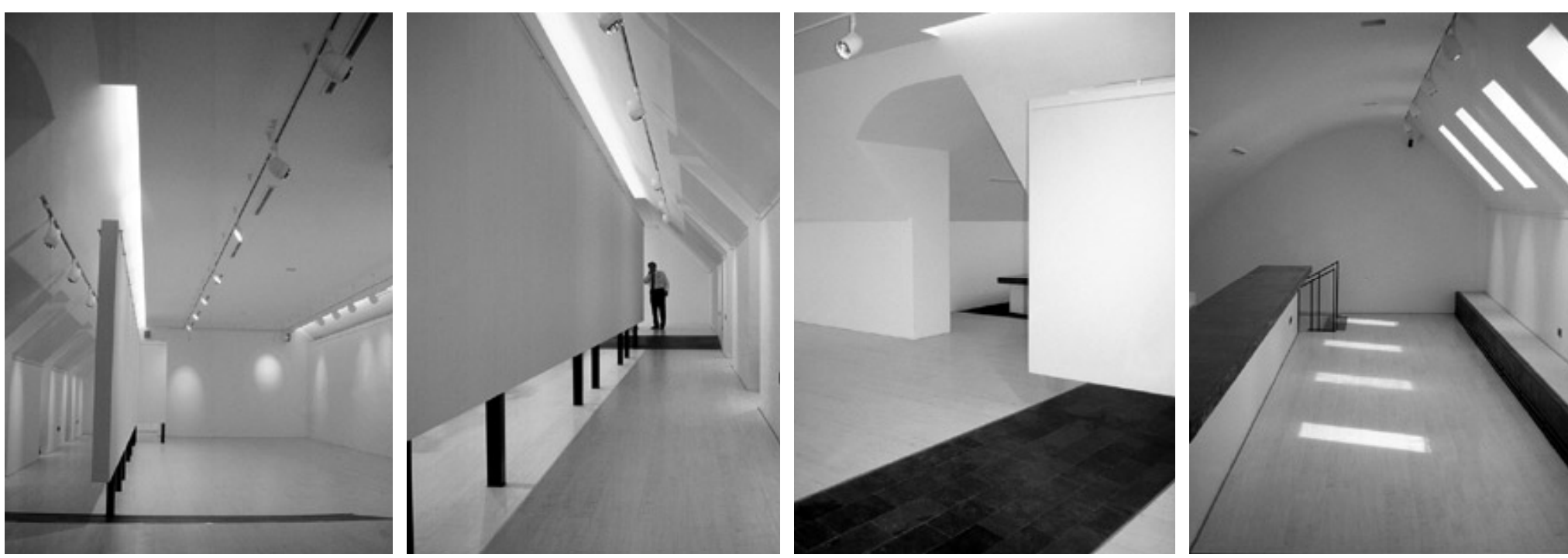

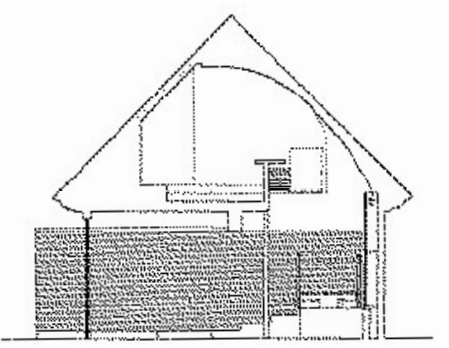

Corte

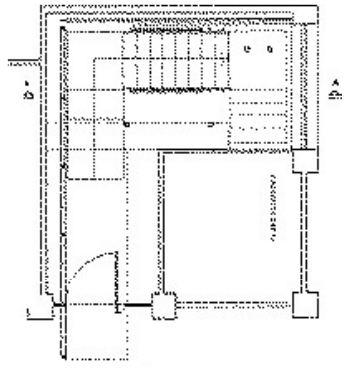

Planta de acceso, primerpiso 